\title{
UM PASSEIO PANORÂMICO PELA PRODUÇÃO LITERÁRIA INFANTO- JUVENIL MOÇAMICANA: AUTORES E OBRAS ${ }^{1}$
}

\author{
Maria Anória de Jesus Oliveira²
}

\begin{abstract}
Resumo: O presente texto visa a apresentação panorâmica da produção literária infanto-juvenil moçambicana contemporânea. Para tanto, realizamos a pesquisa bibliográfica em Maputo, entre o período de maio a outubro de 2009. Identificamos temas diversificados abrangendo-se desde o patriotismo às problemáticas sociais, a exemplo da guerra, da orfandade, da pobreza e do predomínio das narrativas tradicionais. Os personagens, de modo geral, são apresentados com fenótipos negros nas ilustrações, muito embora sem referencia a tais traços na linguagem verbal. Esperamos, através desse estudo, colaborar para visibilizar tais produções no mercado livresco, haja vista a carência de pesquisas acerca delas tanto em Moçambique quanto no Brasil.

Palavras-Chave: Literatura infanto-juvenil moçambicana; Personagens; Narrativa.
\end{abstract}

\begin{abstract}
This text aims to show a panoramic presentation of contemporary children literature production in Mozambique. So, we did a bibliographic research in Maputo, between May and October in 2009. We identified various themes from patriotism to social problems, as war, orphanage problems and poverty, and we sow a good quantity of traditional narratives. The characters, in a general perspective, are presented in a negro shaped, but not at the same strength in the verbal language. So, we hope, from this study, collaborating to make this production visible to the book shopping market, because there is not enough research in this area, including Brazil and Mozambique. Keywords: Mozambique children literature; Characters; Narrative.
\end{abstract}

1 Para maiores detalhes acerca de tal estudo, consultar a tese de doutoramento intitulada: Personagens negros na literatura infanto-juvenil brasileira e moçambicana (2000 2007): entrelaçadas vozes tecendo negritudes (defendida em 2010), na qual fizemos a análise de dez narrativas infanto-juvenis, sendo quatro brasileiras, uma traduzida no Brasil e cinco moçambicanas, através da concessão da bolsa sanduiche CAPES, que possibilitou a permanência em Maputo por cinco meses, a fim de realizarmos o levantamento bibliográfico e as respectivas análises. Tal tese se encontra disponível no seguinte site: http://bdtd.biblioteca.ufpb.br/tde_busca/arquivo.php?codArquivo=1609 (parte 1) e: http://bdtd.biblioteca.ufpb.br/tde_busca/arquivo.php?codArquivo=1610 (parte 2).

2 Professora Adjunto da Universidade do Estado da Bahia (UNEB), Campus II, da Graduação e do Programa de Pós-Graduação em Crítica Cultural (Pós-Crítica); Doutora em Letras pela Universidade Federal da Paraíba (UFPB); pesquisadora de relações étnico-raciais. Endereço eletrônico: anoriaoliveira@uneb.br e anoriaoliveira@yahoo.com.br. 
Se, por um lado, no caso do Brasil, ainda se está à procura de um espaço para os personagens negros na vasta literatura infanto-juvenil, nosso contexto é outro, estamos à procura de um espaço para a literatura infantil como forma de expressão literária [...] (Alberto da Barca) $)^{3}$.

\section{INTRODUÇÃO}

Embora tenhamos realizado um estudo aprofundado sobre a literatura infanto-juvenil moçambicana, a fim de situá-la historicamente, destacar os principais autores e identificar até onde é possível estabelecer relação com a produção brasileira, no que se refere à tessitura dos seres ficcionais, em virtude do exíguo espaço para maiores explanações, no presente artigo nos limitaremos a apresentar uma visão panorâmica dessa produção ${ }^{4}$.

Como visamos o mapeamento das referidas produções e não a análise, nesse breve dialogo salientamos que, no estudo precedente, nos norteamos na teoria literária, na crítica e em subsídios oriundos das Ciências Sociais, dentro da perspectiva étnico-racial.

As idéias desenvolvidas seguem o ponto de vista de Sartre (1968) e Kabenguele Munanga (1999), no que se refere às relações étnico-raciais, isto é, às complexas relações entre negros e brancos no panorama mundial, as quais se configuram, também, nas produções literárias. Do campo da linguagem e da teoria literária recorremos às abordagens que não se restringem à imanência, à leitura intrínseca meramente, pois a composição artística emerge das relações internas (personagens, narrador, tempo, espaço) e externas (o contexto social). Dentre das abordagens que seguem esse viés recorremos a Fiorin (1991), Eagleton (1993), Candido (1973; 1999), Khede (1990), Compagnon (2001), Cuti (2002) e Noa (2009).

Pensar a literatura infanto-juvenil sob o prisma das crianças e jovens implica propiciar personagens que agem e, de algum modo, exprimem o seu universo emocional constituído de conflitos, dinamicidade e ludicidade. Daí ser possível extravasar emoções bloqueadas, salienta Ribeiro (1999);

3 Alberto da Barca é um dos fundadores da literatura infantil moçambicana, dos anos 80 . A epígrafe consiste da sua fala quando do evento intitulado: Literatura infanto-juvenil brasileira e moçambicana contemporânea: problemas e perspectivas, realizado na Associação de Escritores Moçambicanos (AEMO), dia 7 ago. 2009. Nesse evento versaram sobre a sua produção os seguintes escritores: Angelina Neves, Rogério Manjate, Mário Lemos e o referido escritor, Alberto da Barca.

4 Para maiores informações e aprofundamentos teóricos da análise, consultar a tese, na íntegra, disponível no site: http://bdtd.biblioteca.ufpb.br/tde_busca/arquivo.php?cod Arquivo=1609.

80 Número temático: Literatura, cultura e memória negra. A Cor das Letras - UEFS, n. 12, 2011 
inconscientes, amplia Bettelheim (1983), referindo-se aos contos de fadas. Considerando essa premissa, situaremos a trajetória histórica da literatura infanto-juvenil em Moçambique, as temáticas predominantes e destacaremos, por fim, as obras que tem se destacado na contemporaneidade. Estas obras, a nosso ver, sugerem leituras do universo circundante por meio dos seres ficcionais e do espaço social delineado nas narrativas.

\section{NAS TRILHAS DA PESQUISA}

A despeito do parco investimento na produção infanto-juvenil moçambicana, a qual sobrevive graças aos guerreiros empreendedores da área, a saber, os/as escritores/as, editoras, as ONGs, além dos órgãos responsáveis pela viabilização do objeto livro na região, se percorrermos as principais livrarias de Maputo, tendemos a nos decepcionar com a escassez de tais produções.

Além dos escritores, para não nos limitarmos às escassas prateleiras das livrarias, recorremos ao acervo do Instituto Camões, da Associação Progresso, situados em Maputo e, ainda, a Associação dos Escritores Moçambicanos (AEMO), as editoras: Promédia, Ndjira e a Texto Editores. Esse percurso implicou em uma espécie de garimpagem cuidadosa, paciente e possibilitou, ao final, que nos surpreendêssemos diante da quantidade significativa de tal produção. O resultado do percurso foi uma farta mesa forrada por diversos livros coloridos, muito embora alguns tragam imagens em preto e branco no seu corpus, configurando temáticas diversas.

Encontraremos, entra as produções moçambicanas, desde o patriotismo às consequências da guerra, a exemplo da orfandade em uma delicada cena ilustrada, na qual se projeta a explosão do corpo de uma mãe lançada ao ar, por uma mina, sob o perplexo olhar do filho (O menino Octavio). Temos, ainda, a orfandade resultante da SIDA, tema recorrente na literatura infanto-juvenil moçambicana. Há um número ínfimo de obras que trazem a pobreza de pequenas personagens esfomeados no mundo das ruas. Ain$\mathrm{da}$, as peraltices do Coelho que nem sempre leva a melhor, entre outras lendas oriundas dos contos tradicionais, e as recentes aventuras de dois irmãos, os gêmeos, que percorrem as províncias da região, desafiando perigos adversos. Os personagens, de modo geral, são apresentados com fenótipos negros nas ilustrações. 


\section{INDEPENDÊNCIA POLÍTICA E “RENASCIMENTO” LITERÁRIO}

Muito embora tenhamos identificado uma quantidade significativa de obras literárias destinadas às crianças e aos jovens, em Maputo, estas praticamente não circulam no mercado editorial local e, menos ainda, em grande parte do espaço escolar. Excetuam-se os livros recentemente publicados por Texto Editores e outras editoras da região, mas o número de livros expostos nas livrarias de Maputo é ínfimo.

No que se refere às traduções, localizamos poucas. Algumas são procedentes dos contos de fadas e/ou outras oriundas da editora portuguesa intitulada Caminho, cuja filial situa-se em Maputo. Há, também, textos oriundos das narrativas orais. Alguns adaptados ao universo dos leitores e outros não, apenas ilustrados e editados. No entanto, conforme Carmem L. Tindó Secco $(2007$, p. 9)

Fabular, contar casos, reinventar missossos e outras estórias da oratura africana, recriar tradições por intermédio de modernas estórias está na alma de diversos escritores angolanos e moçambicanos que, principalmente depois da independência, começam a publicar textos dirigidos a crianças e jovens.

Mas, ressalta a referida pesquisadora, os "contos tradicionais africanos" e os "textos da literatura infanto-juvenil de Angola e Moçambique, até agora", têm sido "pouco estudados nos meios acadêmicos literários brasileiros" (SECCO, 2007, p. 9).

A afirmação de Secco é pertinente visto que, em Moçambique, notamos a escassez de informações escritas sobre a área nos dias atuais. Tanto é que, para a presente pesquisa, contamos apenas com os diálogos verbais com os respectivos escritores e três breves textos resultantes de um relatório acerca de palestra sobre a literatura infantil, realizada no dia do escritor moçambicano, 7 de novembro de 2003, em Maputo. Tais textos contribuem para demarcar o percurso histórico da literatura infanto-juvenil moçambicana. Dois deles escritos por Baltazar Macamo (2003) e Rogério Manjate (2003), trazem contribuições para identificarmos a trajetória quantitativa das publicações e, de certo modo, das temáticas predominantes quando do "renascimento" destas nos últimos tempos.

Como a literatura infanto-juvenil parece originária do final dos anos 70, precisamente em $1979^{5}$, após a publicação de quatro livros, conforme

5 No que se refere à origem da literatura infanto-juvenil enquanto produção escrita, não podemos afirmar que antes de 1979 não havia livros editados em Moçambique, mas consideramos pertinente o relato de Baltazar Macamo, o qual resulta de dados oficiais da

82 Número temático: Literatura, cultura e memória negra. A Cor das Letras - UEFS, n. 12, 2011 
consta do relatório de Macamo (2003), podemos inferir que seu nascimento no âmbito da escrita ocorreu na pós-independência. Época essa marcada pela re-construção do nacionalismo moçambicano, após tantos anos de conflitos internos no país. Logo, salienta Macamo (2003):

\begin{abstract}
A recolha bibliográfica efectuada por António Sopa e Júlio Navarro, entre 1975 e agosto de 98, confirma que a produção literária infantil em Moçambique começou em 1979 com a edição de quatro novos títulos; em 1980, dezesseis; 1981, dez, tendo-se depois seguido uma fase de declínio entre 1987 e 1990 por a cultura ter sido relegada para segundo plano devido à instabilidade provocada pela guerra.
\end{abstract}

Considerando a colocação acima, temos: 1) $1979=4$ livros; 2) $1980=$ 16 livros; 3) 1981 = 10 livros; 3) 1987-1990 declínio, devido à guerra. Portanto, só a partir de 1990 se iniciou o "renascimento da literatura infantil", segundo Macamo, devido às "novas iniciativas" na área. Nesse período a Secretaria de Estado para a Ação Social "lançou no mercado dez títulos"; o UNICEF "assumiu projectos de livros infantis publicando cerca de quarenta novos títulos", salienta o relator. Inclusive Ziraldo, reconhecido na literatura infanto-juvenil brasileira, foi a Moçambique para "treinar moçambicanos na arte de escrever e desenhar para crianças". Macamo complementa ainda que: "Dessa iniciativa foi produzido um livro conjunto a partir de um conto tradicional moçambicano, 0 Homem e os Macacos. Eis, assim, a criação de "uma nova geração de fazedores de livros infantis", em Moçambique, conclui.

Angelina Neves é a precursora dessa literatura desde as publicações do folheto do jornal Njingiritane, destinado às crianças e jovens. Tal folheto atualmente está sob a responsabilidade de Mário Lemos, outro escritor do gênero literário que reconhece ter sido Angelina sua grande inspiradora e

época, levando em conta os órgãos responsáveis pelas publicações em Moçambique, contando-se também com a presença dos principais escritores, além dos representantes do Ministério da Educação (MINED) e do Instituto do Desenvolvimento da Educação (INDE). Daí inferirmos que a literatura infanto-juvenil moçambicana tem sua origem no final dos anos 70, e seu "renascimento" a partir de 1990, quando dos investimentos maiores por parte das ONGs e demais órgãos que viabilizaram a inserção de uma quantidade significativa de livros, embora estes não circulassem, pois eram concebidos para determinados espaços educativos, especificamente via concursos, e não para serem disponibilizados no mercado livresco, a exemplo das

livrarias e demais editoras. Não podemos esquecer que a sociedade saía das eras conflituosas do colonialismo, sendo a pós-independência marcada pela devastadora guerra civil e que só a partir de 1992 é que a sociedade começa a respirar um pouco de paz no ambiente social. 
mentora desde a época em que ele, na juventude, mergulhava no universo literário dos textos contidos naquele suplemento por ela coordenado. Alberto da Barca também desempenhou papel pioneiro investindo em tal produção nos anos 90 .

Em se tratando dos órgãos que investiram na literatura infantojuvenil moçambicana, Macamo (2003) assevera que

A partir de 1990, as principais iniciativas para a produção do livro infantil passam também a pertencer as ONG's e editoras privadas, que drenaram um verdadeiro renascimento da literatura infantil. Estima-se em mais de 130 os títulos de autores com preparação técnica reconhecida.

A Coopimagem, a Associação Progresso, a Fundação Bernard Van Liar, a APOSEMO, a Editora Escolar e a Editora Ndjira, por sua vez, estimularam a recolha de contos tradicionais moçambicanos em todo o país, durante os últimos anos. Há que se referir a MINED que tem se interessado pela reimpressão de alguns livros.

Diante desses dados notamos que o "renascimento" da literatura infanto-juvenil moçambicana se inicia, de fato, no final da pós-independência, a partir de 1990, sob a tutela de importantes orgãos locais apoiados por instituições internacionais. Mesmo assim, grande parte das obras não circulam no mercado editorial, devido à falta de maiores investimentos na região.

\section{TEMÁTICAS PREDOMINANTES}

Antes de percorrermos o universo das narrativas infanto-juvenis moçambicanas é imprescindível fazermos elucidações no tocante aos personagens, os quais, enquanto elementos constitutivos da narrativa, sugerem leituras do seu modo de ser e de se relacionar com o mundo (CANDIDO, 1992). Mundo esse perscrutado através da voz do narrador, quando relata

a história utilizando-se da primeira e da terceira pessoa do singular ou do plural. Sua voz nos guia e amplia a leitura das ilustrações. Estas tendem, também, a reconfigurar o texto verbal, antecipar cenas, fatos e as ações dos seres ficcionais.

Grande parte da produção literária infanto-juvenil, conforme salienta Zilberman (1982), é uma produção produzida, comprada e trabalhada pelo adulto. Sendo assim, salienta Palo (2005), os principais destinatários praticamente não têm "voz", diante dos textos que lhes são designados. Nisso consiste a assimétrica relação entre a literatura infanto-juvenil e o leitor, posto que prevalece o ponto de vista do adulto que almeja incutir sua con- 
cepção de mundo para as crianças e jovens, lhes ensinado sobre os problemas sociais, morais, religiosos, etc.

Partindo das asserções de Zilberman podemos inferir que, em se tratando das narrativas infanto-juvenis publicadas em Moçambique, salvo raras exceções, prevalece a finalidade educativa, visando-se à transmissão de ensinamentos aos destinatários, seja por meio dos problemas sociais e/ou das lições de moral. São ainda poucas as obras que se distanciam de tais propósitos. Foi o que constatamos em grande parte dos textos provenientes da tradição oral, entre outros. A leitura lúdica, voltada para o universo das crianças e jovens, em suas questões existenciais, permanece escassa.

As personagens, em tais produções, desempenham papéis sociais diversificados, situados nas zonas rurais, aldeias, e/ou nos centros urbanos. Prevalece o relato de fatos ocorridos e menos as ações de tais seres. Aliás, praticamente não se descrevem os seus traços físicos no que se refere aos cabelos, cor da tez, aos fenótipos diacríticos. Estes são identificados por meio das ilustrações, grosso modo. No entanto, é comum haver alusão aos comportamentos, à educação, ao afinco estudantil, inteligência, astúcia, enfim, o que expressa índole imaculável.

\section{ESCRITORES E PRODUÇÃO LITERÁRIA INFANTO-JUVENIL CONTEMPORÂNEA}

Partindo da pesquisa bibliográfica que realizamos em Maputo relacionamos, por ordem alfabética, os autores que publicaram livros infantojuvenis destinados às crianças e jovens, são eles ${ }^{6}$ :

a) Alberto da Barca, um dos precursores e importante investidor na área ao final das lutas armadas, prosseguindo também até meados dos anos 90;

b) Angelina Neves, educadora, a grande precursora da literatura infanto-juvenil moçambicana, que prossegue produzindo ainda nos dias atuais. A escritora produz também livros didáticos para a fase pré-escolar e é, ainda, ilustradora, tendo passado suas ilustrações pelo crivo de Ziraldo, anos atrás;

c) Calane da Silva, que tem publicações para os adultos; recentemente lançou dois livros destinados ao público infanto-juvenil. Um deles é sobre a poesia;

6 Descrevemos as atividades dos escritores, conforme informações obtidas via contato com os mesmos ou por meio das informações constantes dos seus textos. 
d) Carlos dos Santos. Desse escritor tivemos acesso a dois livros apenas, os quais resultam dos contos tradicionais;

e) Felizmina W. Velho, que tem publicado contos tradicionais;

f) Machado da Graça, jornalista, recentemente vem investindo na publicação e na editoração de alguns livros através da série $O s$ gémeos, personagens astutos que percorrem diversas províncias do país e ajudam a resolver situações problemas (rapto de crianças, roubo de gados, caçadores furtivos, tráfico, feitiçaria);

g) Mário Lemos, educador e escritor da área, vem privilegiando a problemática social - a SIDA - em duas obras. Esse escritor tem uma publicação no Brasil: A semente que veio da África, em coautoria com Heloisa Pires Lima;

h) Mia Couto, reconhecido escritor no panorama nacional e internacional, nos últimos tempos tem se voltado também, para a literatura infanto-juvenil;

i) Pedro Muiambo, recente nessa área, vem produzindo mais dentro do prisma dos contos tradicionais;

j) Rogério Manjate, artista da área teatral, educador, tem produzido poesia "para todas as idades", conforme subtítulo de um dos seus livros, e um recente infanto-juvenil editado pela editora Ática.

Ao fazer o apanhado geral das principais temáticas concernentes aos livros publicados em Moçambique, nos pautamos na leitura das obras dos escritores ${ }^{7}$ acima aludidos. Salientamos, no entanto, que pode haver mais escritores na região, e a relação ora apresentada não visa à exclusão dos mesmos. Aqui nos limitamos tão somente às obras a que tivemos acesso durante os cinco meses de pesquisa bibliográfica, levando em consideração as que nos foram disponibilizadas pelos autores com os quais tivemos contato, e ainda os livros adquiridos via instituições locais ${ }^{8}$.

No tocante às temáticas predominantes, estas giram em torno das questões sociais, prevalecendo o realismo, excetuando-se os contos tradicionais e algumas obras que recorrem aos recursos fantásticos e maravilho-

7 A título de nota, observemos que a maioria das publicações é de autoria masculina, havendo só duas mulheres, Angelina Neves e Felizmina Velho. Isso evidencia que tal produção é uma atividade, sobretudo, masculina no país.

8

A exemplo da Associação Progresso, Fundo Bibliográfico de Língua Portuguesa, Associação de Escritores Moçambicanos, Instituto Português Camões e algumas Editoras que vêm publicando na área, a Texto Editores e a Ndjira, assim como as principais livrarias situadas em Maputo.

86 Número temático: Literatura, cultura e memória negra. A Cor das Letras - UEFS, n. 12, 2011 
sos. Há, ainda, a humanização de seres inanimados em alguns textos ${ }^{9}$, levando-nos a percorrer o seu imaginário através da voz dos narradores oniscientes, quando desvelam a interioridade, desejos ou instigações, dúvidas, receios, angústias e dos anseios das personagens.

Destacam-se, na contemporaneidade, entre a produção moçambicana a série os Gémeos, de autoria de Machado da Graça ${ }^{10}$. São eles: 1) Os gémeos e os traficantes (2003); 2) Os gémeos e os caçadores furtivos (2005); 3) Os gémeos e os ladrões de gado (2005); 4) Os gémeos e a feiticeira (2005); 5) Os gémeos e os raptores de crianças (2007); 6) Os gémeos e os ladrões de tesouros (2008). Outras séries serão lançadas em breve, conforme o escritor.

A série os Gémeos resulta de concursos anteriores promovidos pela Associação Progresso, em Maputo, vencidos por Machado da Graça. Tendo obtido premiações, o referido jornalista passou a investir na área e, recentemente, em parceria com a Associação, edita seus livros, assim como os de outros escritores moçambicanos. A série já tem seis livros publicados até então, e algumas reedições.

Por meio de cada narrativa percorremos algumas províncias de Maputo e conhecermos um pouco das singularidades das povoações, além de um determinado problema que afeta uma comunidade, um fazendeiro; enfim, uma região, no geral, ou uma família, em particular.

As histórias abordam problemas sociais por meio das aventuras vivenciadas por dois irmãos Isa e Zé, pertencentes à classe social alta, posto que viajam de avião, entre outros meios de transportes, vivenciando aventuras nas férias, no cotidiano de visita a um parente, em um passeio; enfim, em situações nas quais eles, bons observadores, desempenham papéis de investigadores ao notarem irregularidades que até a polícia desconhece.

Os pais de Isa e Zé, às vezes, se envolvem nas aventuras e ajudam os filhos na resolução do problema. Entre estes há (1) o tráfico de drogas "na Praia de Ponta de Ouro" (Os gémeos e os traficantes); (2) o roubo de animais no Parque Nacional do Limpopo (Os gémeos e os caçadores furtivos; (3) o roubo de gados em Gaza (os gémeos e os ladrões de gados); (4) rapto de crianças para fins de tráfico na África do Sul (Os gémeos e os raptores de crianças); (5) o roubo de relíquias e jóias em um navio náufrago na Ilha de

9 Essa é uma herança dos contos tradicionais, das lendas que permeiam os textos contemporâneos. Alguns destes são de autoria de Angelina Neves, Alberto da Barca e Rogério Manjate.

10

Todas as obras são escritas com a seguinte grafia: Gémeos. 
Moçambique, situada na província de Nampula (Os gêmeos e os ladrões de tesouros); (6) a resolução de um mistério, envolvendo uma senhora acusada de feitiçaria (Os gémeos e a feiticeira). Nesta última narrativa, quem mais pratica ação com vistas à solução o problema é a mãe dos gêmeos, que nascera na região, e eles mais acompanham os fatos no desenvolver da trama.

$A c ̧ a \tilde{o} o^{11}$, aventura e dinamicidade é o que não falta à vida dos protagonistas, os quais simbolizam os heróis contemporâneos que, ao invés de "varinhas de condão" e/ou palavra mágica, contam com a astúcia, ajudando a salvar vidas contribuindo, desse modo, para redimensionar nosso olhar face ao universo social local e, mais, envolvem os leitores no delicioso mundo da leitura. Eis, a nosso ver, um dos papéis cruciais da série Os gé$m_{e o s}{ }^{12}$.

Diferentemente das demais obras que fazem pouca alusão ao espaço social, em Os gémeos e os raptores de crianças, por conta do rapto de Isa e da movimentação para resgatá-la, o narrador e alguns personagens fazem alusão a bairros de Maputo e à fronteira da África do Sul. Entre os bairros situados na capital moçambicana, uns aparecem nas ilustrações e outros são apenas mencionados através da voz do narrador ou das personagens, abrangendo a zona urbana (p. 4 ; 28). Faz-se menção à Baixa, um bairro antigo da capital (p. 12) e à zona rural (p. 5 e 6$)^{13}$. Da África do Sul, destacase a fronteira Ressano Garcia (p. 16), o imenso Kruger Parque (p. 22), a África do Sul (p. 26), Johanesburgo (p. 24 e 29) Komatipoort e Malelane (p. 29). Ou seja, esta obra corrobora para visualizarmos um pouco da constituição geográfica de Maputo e da África do Sul. Isso destoa da idéia de uma África situada em um tempo remoto, reduto só de zebras e demais animais.

Outra narrativa que situa o espaço social moçambicano é $O$ menino Octávio, fazendo-se alusão ao distrito de Mavago Nsawizi, localizado na

11 Entendemos a ação na mesa perspectiva de Propp (1984.), que se detém sobre os contos maravilhosos e, a partir das ações e das funções praticadas pelos personagens se identifica a importância deles no desenvolver da trama.

12 Autoria de machado da Graça. Veja-se, ao final do presente texto, a referencia completa e o ano de publicação da referida obra: Os gémeos e os raptores de crianças (GRAÇA, 2007).

13 Tanto a zona urbana (p. 4) quanto a rural aparecem na ilustração (pg. 6 e 8); também as mobilizações para resgatar Isa perpassam pela zona rural e urbana (p. 11; 15; 18; $21 ; 2$ ) e na fronteira entre Moçambique e África do Sul (p. 31).

88 Número temático: Literatura, cultura e memória negra. A Cor das Letras - UEFS, n. 12, 2011 
zona rural ${ }^{14}$. Além de Os gémeos e os raptores de crianças e $O$ menino Octávio, que situam os respectivos espaços sociais, as demais apenas demarcam a zona rural ou urbana, mas sem alusão a um país especificamente.

As zonas urbanas e rurais podem ser identificadas também em Mbila $e$ o coelho, visto que as ações praticadas pelos personagens ocorrerem na cidade, e o ambiente é a residência de Mbila. Quando ela conta as aventuras do coelho, as situa na zona rural (p. 8, 9; p. 10; p. 16; p. 28-31, entre outras). Da zona urbana citamos dois exemplos. Um é o momento em que a mãe, de madrugada, mostra a "rua" à filha (p. 3); o outro é após sua internação no "hospital" (p. 36), e quando da alusão ao "leão aqui na cidade" (p. 39).

No que se refere aos traços diacríticos dos protagonistas estes não são evidenciados na linguagem verbal e sim através das ilustrações. Inclusive, todos os personagens sejam os principais ou secundários, delineados individualmente ou em grupo, têm traços negros realçados por meio da tez, cabelos e demais aspectos físicos, como os lábios e o nariz. As obras fazem jus à grande parcela da população no país que é massivamente constituída pelo segmento representado nas narrativas, os quais chegam ao patamar dos $99 \%$ por cento, com base no censo de $2007^{15}$.

Os escritores de Literatura infanto-juvenil, conforme diálogos que tivemos, a exemplo de Angelina Neves, Alberto da Barca, Rogério Manjate e Mário Lemos pensam ser a questão étnico-racial um problema recorrente no Brasil, o que pode ser configurado através das nossas obras destinadas às crianças e jovens. Surpreenderam-se, inclusive, com os estereótipos veiculados por meio dos personagens negros e brancos, apresentando-se aqueles como inferiores e estes em funções superiores. Isso nas obras moçambicanas não ocorre, segundo eles. Falta-lhes, na realidade, espaço para a literatura infanto-juvenil e, no Brasil, falta espaço para os personagens negros nas obras, salientou Alberto da Barca.

A afirmação dos escritores pode ser observada nas obras moçambicanas, as quais não trazem à tona a problemática das relações étnico-raciais em sua tessitura. E a linguagem verbal não ressalta os traços diacríticos das personagens, exaltando-se a beleza dos cabelos, a cor da tez, enfim, os fenótipos negros. Por outro lado, essas narrativas contemporâneas não

14 É importante informar que as províncias foram os espaços mais atingidos pela luta armada pós- independência. Algumas delas, entre outras, são Nhambane e Gaza.

15 Fonte: http://www.ine.gov.mz/censos_dir/recenseamento_geral/estudos_analise/nacio nalidades. 
deixam de ilustrar tais traços. Em Os gémeos e os raptores de crianças, logo na capa, a protagonista está com os cabelos presos em forma de popa, atrás, e assim permanece em toda a trama. Também Miriam (p. 25) tem cabelos crespos. O pai, irmão, os antagonistas e a polícia são negros.

\section{CONSIDERAÇÕES (IN)CONCLUSIVAS}

Considerando a visão panorâmica acerca da produção literária infanto-juvenil moçambicana, apresentamos alguns escritores e as temáticas predominantes, no intuito de ressaltar a importância da mesma e despertar nos leitores interesse por essa desconhecida produção. Fica, portanto, o convite ao seu deleite e esboçamos, por fim, breves sugestões, com vistas a conhecer sua composição artística.

Caberia um estudo comparativo acerca das temáticas predominantes, a exemplo da SIDA, do papel dos personagens, da descrição espacial, da voz do narrador, dos contos tradicionais e dos traços diacríticos dos seres ficcionais. Em Os gémeos e os raptores de crianças a protagonista Isa é delineada com os cabelos presos em forma de popa, atrás, e assim permanece em toda a trama. Também Miriam (p. 25) tem cabelos encaracolados. 0 pai, irmão, os antagonistas e a polícia são negros.

Em cada série do livro Isa aparece com penteados variados. É ilustrada com birotes enfeitados (Os gémeos e os traficantes), com tranças tipo nagô (Os gémeos e os ladrões de tesouro), com um penteado tipo black power (Os gémeos e os ladrões de gado), com tranças raiz (Os gémeos e a feiticeira), com os cabelos soltos, trançados, enfeitados com miçangas nas pontas (Os gémeos e os caçadores furtivos). Compreendemos, com isso, que a coleção Os gémeos, através da protagonista Isa, expressa a riqueza dos diversos e belos penteados utilizados no cotidiano de grande parte das crianças e jovens moçambicanas.

Consideramos de extrema relevância, ainda, estudos sobre as duas versões de Mbila e o coelho, da autoria de Rogério Manjate (2007), editada recentemente no Brasil pela editora Ática, com o título: $O$ coelho que fugiu da história (2009). É importante nos atentarmos que na edição brasileira há uma espécie de embranquecimento da personagem, diferentemente da versão original. Esse fato muito nos instigou e expressa que nossas produções, a despeito das mudanças recentes, após a obrigatoriedade de estudos para as relações étnico-raciais e para o ensino da história e cultura afro- 
brasileira, africana e indígena prossegue, sobretudo, eivada de eurocentrismo ${ }^{16}$.

Enfim, há um universo imerso em significações a ser desvendado nas produções moçambicanas, há carência de investimento na área, conforme destaca Alberto da Barca na epígrafe citada inicialmente. Há negros personagens ilustrados por meio da linguagem não verbal, muito embora não descritos em seus traços constitutivos que requerem pesquisas; há narradores enredando seres ficcionais em espaços sociais não reduzidos aos estereótipos negativos em face de uma pequena parte do vasto continente que gestou a humanidade. Nosso intuito aqui foi deixar um pequeno legado para quem desejar seguir essa linha de estudos, a qual carece, ainda, de muitas pesquisas.

\section{REFERÊNCIAS}

ATANÁSIO, Calisto; NEVES, Angelina; CIRÍACO, H. O menino Octávio. Moçambique: Ndjira, 2003. [Adaptação].

BETTELHEIM, Bruno. A psicanálise dos contos de fadas. Rio de Janeiro: Paz e Terra, 1978.

COELHO, Nelly. A literatura infantil: história, teoria, análise. São Paulo: Ática, 1993.

CUTI. [Luis Silva]. O leitor e o texto literário. In. FIGUEIREDO, Maria do Carmo; FONSECA, Maria Nazareth S. Poéticas afro-brasileiras. Belo Horizonte: Mazza: PUC-Minas, 2002, p. 936.

EAGLETON, Terry. Teoria literária. São Paulo: Martins Fontes, 1983.

FIORIN, J. L. Linguagem e ideologia. São Paulo: Ática, 1991.

GRAÇA, Machado. Os gêmeos e os raptores de crianças. Moçambique, Promédia/Associação Progresso, 2006.

KHÉDE, Sônia Salomão. Personagens da literatura infanto-juvenil. São Paulo: Ática, 1990 MACAMO, Baltazar e MANJATE, Rogério. Literatura infantil em Moçambique. Maputo, 2003. [Mimeo].

MANJATE, Rogério. Mbila e o coelho: história para todas as idades. Moçambique: Ministério da Educação/Escola Portuguesa de Moçambique, 2007. Col. Acácia.

MANJATE, Rogério. O coelho que fugiu da história. São Paulo: Ática, 2009.

NOA, Francisco. As falas das vozes desocultas: a literatura como restituição. In: GALVES, Charlotte, et al. (Org.). África - Brasil: caminhos da Língua Portuguesa. Campinas: Ed. Unicamp, 2009, p. 85-101.

16 Excetuando-se tal alteração, a edição brasileira é enriquecida no tocante à diagramação das páginas e da composição artístico do ilustrador. 
OLIVEIRA, Maria Anória de J. Negros personagens nas narrativas literárias infanto-juvenis brasileiras: 1979-1989. 2001. Dissertação (Mestrado em Educação) .- Departamento de Educação da UNEB, Salvador, 2003.

OLIVEIRA, Maria Anória de Jesus. Personagens negros na literatura infanto-juvenil brasileira e moçambicana (2000-2007): entrelaçadas vozes tecendo negritudes. Tese (Doutorado em Letras). Departamento em Letras, UFPB, João Pessoa, 2010.

PALO, Maria José. Literatura infantil voz da criança. São Paulo: Ática, 2006.

PROPP, Vladimir. Morfologia do conto maravilhoso. Trad. Jasna P. Sarhan. Rio de Janeiro: Forense Universitária, 1984.

RIBEIRO, Jonas. Ouvidos dourados: a arte de ouvir histórias (... para depois contá-las...). São Paulo: Ave Maria,1999.

SARTRE, Jeal-Paul. Jeal-Paul. Reflexões sobre o racismo. São Paulo: Difusão Européia do Livro. 1968, p. 89-125.

SECCO, Carmem Lúcia Tindó. (Org.). Entre fábulas e alegorias: ensaios sobre literatura infantil de Angola e Moçambique. Rio de Janeiro: Quartet: UFRJ, Centro de Letras e Artes, 2007.

ZILBERMAN, R.; MAGALHÃES, Ligia Cademartori. Literatura infantil: autoritarismo e emancipação. São Paulo: Ática, 1982. 